\author{
ОРГАНИЗАЦИЯ ВЕТЕРИНАРНОГО НАДЗОРА \\ ЗА СВИНОВОДЧЕСКИМИ ХОЗЯЙСТВАМИ ВОЕННО- \\ СТРОИТЕЛЬНЫХ ОТРЯДОВ В Г. ЖЕЛЕЗНОГОРСКЕ \\ (КРАСНОЯРСК-26) В ПЕРВОЙ ПОЛОВИНЕ 1960-Х ГГ.
}

\title{
G.A. Reut
}

\section{THE ORGANIZATION OF VETERINARY SUPERVISION OF PIG FARMS OF MILITARY CONSTRUCTION UNITS IN ZHELEZNOGORSK (KRASNOYARSK-26) IN THE FIRST HALF OF THE 1960-S}

Цель исследования - выявить проблемы в организации ветеринарного контроля за подсобными (прикухонными) животноводческими хозяйствами войсковых частей Управления военно-строительных отрядов, дислоцировавшихся на строительстве секретного объекта Министерства среднего машиностроения в г. Железногорске. Исследование охватывает период с 1960 по 1965 г. и основано на документах и материалах Железногорского городского архива, в том числе на решениях исполкома городского совета г. Железногорска, стенограммах выступлений членов исполкома горсовета и лиц, приглашавшихся на заседания исполкома для обсуждения соответствующих вопросов, а также планах карантинных мероприятий, справках СЭС и т. д. В статье проанализированы документы, в которых отражена роль органа местной власти в организации мероприятий, направленных на установление ветеринарного контроля за свиноводческими хозяйствами войсковых частей, принимавиих участие в строительстве основного градообразующего предприятия. Сделан вывод о том, что становление ветеринарного надзора в свиноводческих хозяйствах УВСО прошло через два этапа. На первом этапе в начале 1960-х га. ветеринарно-санитарный контроль за содержанием животных практически отсутствовал, что нередко приводило к массовым заболеваниям и падежу свинопоголовъя. На втором этапе, к середине 1960-х г2. исполком ЖГС при содействии ГК КПСС принял практические меры к повышению роли главного ветеринарного врача города в организации контроля за содержанием животных, в том числе и за свиноводческими хозяйствами военно-строительных частей. Принятые меры позволили повысить санитарное благополучие на территории города, а также прилегающих поселков. 


\section{Социально-экономический и гуманитарный журнал Красноярского ГАУ. 2019. № 4}

Ключевые слова: закрытый город, Железногорск, Красноярск26, Министерство среднего машиностроения, военные строители, животноводство, свиноводство, ветеринария, ветсаннадзор.

The purpose of the publication is to identify the problems in the organization of veterinary control over subsidiary (kitchen) livestock farms of military units of the Department of military construction units stationed at the construction of a secret facility of the Ministry of Medium Engineering in Zheleznogorsk. The study covers the period from 1960 to 1965 and is based on the documents and materials of Zheleznogorsk city archive, shorthand reports of performances of the members of executive committee of city Council and the persons invited to the meetings of executive committee for the discussion of appropriate questions, and also plans of quarantine actions, references of SES, etc. The study analyzes the documents reflecting the role of local authority in the organization of activities aimed at establishing veterinary control over pig farms of military units that participated in the construction of the main city-forming enterprise. It is concluded that the establishment of veterinary supervision in pig farms MMSO passed through two stages. At the first stage in the early 1960-s veterinary and sanitary control over keeping the animals was practically missing, which often led to mass diseases and the death of swine herd. At the second stage, by mid1960-s, the Executive Committee of the ZHCC which with the assistance of the CC CPSU, took practical measures to increase the role of the chief veterinarian of the city in the organization of control over animals keeping, including pig farms of military construction units. The measures taken made it possible to improve sanitary state of the city territory, and also surrounding villages.

Keywords: closed city, Zheleznogorsk, Krasnoyarsk-26, the Ministry of average mechanical engineering, military builders, animal husbandry, pig breeding, veterinary science, veterinary and sanitary supervision.

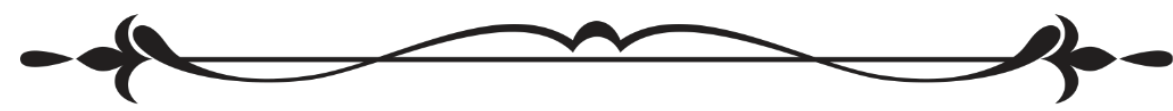

В истории закрытых городов Сибири Министерства среднего машиностроения СССР (далее - МСМ СССР), в том числе г. Железногорска (Красноярска-26), все еще остаются мало изученные аспекты, к одному из них относится развитие подсобного (прикухонного) животноводческого хозяйства военно-строительных частей.

Отдельные вопросы истории сельскохозяйственного производства в закрытых городах МСМ СССР Сибири затронуты в работах автора данной статьи [1].

Деятельность Красноярского совнархоза по организации сельскохозяйственной отрасли, а также общие особенности развития мясной про- 
мышленности региона в рассматриваемые годы отражены в публикациях Р.В. Павлюкевича [2].

Однако в данных публикациях проблемы организации ветеринарносанитарного надзора за подсобными животноводческими хозяйствами военно-строительных частей (далее - в/ч) в закрытых городах МСМ СССР Сибири не затрагивались.

В статье рассматривается период с 1960 по 1965 г. Исследование построено на основе анализа решений исполкома горсовета г. Железногорска (далее - ЖГС), других документов и материалов Железногорского городского архива, касающихся мероприятий, направленных на организацию ветеринарно-санитарного надзора и организацию деятельности главного ветеринарного врача города В.А. Олейникова.

Начало сооружения в Красноярском крае в 1950 г. Горнохимического комбината (далее - ГХК) дало старт строительству секретного населенного пункта - г. Железногорска. На строительстве основного градообразующего предприятия и населенного пункта было задействовано несколько десятков военно-строительных частей Главпромстроя, выполнявшего работы на объектах МСM СССР.

В 1955 г. на строительстве промышленных объектов ГХК и гражданских сооружений в г. Железногорске насчитывалось 27314 военных строителей. В 1960 г. численность военных строителей выросла до 36480 чел. Максимальное количество военнослужащих в 1962 г. 46570 чел. С 1962 г., по мере завершения строительства ГХК, численность военных строителей ежегодно сокращалась и в 1965 г. снизилась до 19 тыс. чел. [3].

Военно-строительные части, дислоцированные на строительстве основного градообразующего предприятия, в рассматриваемый период были подчинены Управлению военно-строительных отрядов (далее $\mathrm{YBCO})$.

Животноводство, в том числе свиноводство, было одним из важнейших направлений в развитии сельского хозяйства в Красноярском крае. Только в 1962 - начале 1963 г. в крае одновременно шло сооружение более 60 свинарников [4].

В г. Железногорске подсобное хозяйство УВСО велось с 1960 года. При крупных войсковых частях были созданы собственные подсобные хозяйства, как правило, предназначенные для содержания свиней [5].

С одной стороны, подсобное хозяйство помогало решать задачу обеспечения контингента военно-строительных отрядов свежим мясом, с другой стороны, свинарники нередко становились источником опасных инфекционных заболеваний.

Так, в 1961 г. клиническими и патолого-анатомическими анализами была подтверждена чума свиней в подсобном хозяйстве в/ч 25597. В целях «недопущения распространения чумы свиней и заноса инфекции в другие хозяйства» исполком ЖГС решением от 18.09.1961 наложил на 


\section{Социально-экономический и гуманитарнъцй журнал Красноярского ГАУ. 2019. № 4}

в/ч 25597 карантин сроком на два месяца, начиная со дня последнего случая заболевания, падежа и убоя свиней.

Командиру в/ч 25597 М.Б. Озиранскому и начальнику ветеринарной инспекции п/я 18 Малкову исполком предписал немедленно вакцинировать всех здоровых свиней и обеспечить выполнение мероприятий, предусмотренных инструкцией по борьбе с чумой свиней.

Контроль за выполнением принятого решения был поручен главному ветврачу города В.А. Олейникову [6].

После проведения карантинных мероприятий по борьбе с чумой свиней в в/ч 25597 и личных хозяйствах граждан, проживавших в отделениях совхоза УРСа, исполком горсовета решением № 336 от 29.11.1961 снял карантин по чуме свиней, наложенный на в/ч 25597 [7].

09.03.1962 г. было принято решение о проведении в войсковых частях диагностических исследований и профилактических прививок «по плану, составленному командованием войсковых частей и согласованному с главным ветврачом города» и под его контролем [8].

Несмотря на принятые профилактические меры, через некоторое время ситуация повторилась. На основании лабораторного исследования, проведенного Красноярской ветеринарно-бактериологической лабораторией, и клинических анализов заболевших животных была установлена чума свиней, теперь уже в прикухонном хозяйстве в/ч 25762.

Во избежание «распространения чумы свиней в в/ч 25762 и заноса инфекции в другие хозяйства города» исполком ЖГС решением от 26.06.1962 наложил карантин по чуме свиней на в/ч 25762 сроком на 2 месяца. Перед снятием карантина предписывалось провести заключительную дезинфекцию и очистку свинарников и прилегающей территории, а также предметов ухода за свиньями и спецодежды.

Исполком ЖГС обязал командира в/ч 20171 Ф.В. Лобазова и начальника ветеринарной инспекции п/я 18 Курилкина немедленно провакцинировать всех здоровых свиней, содержащихся в прикухонных хозяйствах войсковых частей, и обеспечить выполнение всех карантинных мероприятий, предусмотренных инструкцией по борьбе с чумой свиней [9].

Согласно перечню, составленному начальником тыла в/ч 20171 полковником Брук, в войсковых частях, у которых имелось подсобное хозяйство со свинопоголовьем, в общей сложности на 19.04.1963 насчитывалось 14 свинарников, располагавшихся за периметром войсковой части: 3 - в пункте «Майка»; 1 - в районе «Гривка»; 1 - в пункте «Л(«Элка»)»; 1 - на ул. Красноярская; 1 - в районе 33 кв.; 1 - в Соцгороде и 6 - в пункте «П[асека]» [10].

С целью ликвидации негативного соседства с потенциальными источниками инфекционных заболеваний Пленум ГК КПСС в апреле 1963 г. принял решение вынести свинарники за пределы города.

Однако даже такие радикальные шаги не предотвратили вспышку инфекционного заболевания. 
В 1964 г. на прикухонном хозяйстве воинского подразделения УВСО была зафиксирован ящур свиней. Территория города и поселков была объявлена «угрожаемой зоной» [11].

Анализируя ситуацию, которая привела к вспышке ящура в 1964 г., руководство города пришло к выводу о том, что большое количество свинопоголовья заболело ящуром в результате слабого контроля со стороны ветеринарных работников и низкой дисциплины в проведении противоэпизоотических мероприятий [12].

18.06.1965 г. исполком ЖГС заслушал и обсудил информацию о ветеринарном обследовании скота и птицы, в том числе содержавшихся в прикухонных хозяйствах УВСО.

В своем выступлении на заседании главный ветеринарный врач города обрисовал безрадостное состояние дел с ветеринарным обслуживанием в подсобных хозяйствах УВСО следующим образом: «Не было транспорта ... холодные свинарники ... плохо организован выгул ... свиньи не видели травы и не выпускались на пастбища. Свинарники не приспособлены для содержания животных. Площадка для забоя не оборудована и не принята СЭС» и т. д. Уход за свинопоголовьем был оценен как «очень плохой» [13].

В решении исполкома ЖГС, принятом по итогам обсуждения вопросов ветеринарного обслуживания поголовья в животноводческих хозяйствах, констатировалось, что со стороны ветеринарной службы города должных мер к «наведению необходимого порядка в предупредительнопрофилактической работе» не принимается, а систематический контроль за ветеринарным состоянием животных и птицы в хозяйствах совхоза, УВСО, а также находившихся в личном содержании граждан города, отсутствует.

По оценке исполкома ЖГС, главный ветеринарный врач В.А. Олейников «не являлся организующим звеном в работе ветеринарных служб города». В результате ветеринарные специалисты совхозов и УВСО «были предоставлены сами себе, не повышали своих специальных знаний, слабо следили за последними достижениями ветеринарной науки и практики».

Был отмечен ряд недостатков в лечебной и профилактической работе в подсобном животноводческом хозяйстве УВСО: «Животные содержались в приспособленных помещениях, которые ... плохо эксплуатировались. Сантехническое оборудование не действовало». При этом руководство УВСО игнорировало рекомендации ветеринарного врача по содержанию и кормлению животных, что приводило к большому падежу молодняка.

В решении исполкома ЖГС были поставлены в качестве «главных задач» организация ветеринарного обслуживания скота и птицы в хозяйствах совхоза, УВСО и в личном содержании граждан города и населенных пунктов, а также «своевременное и регулярное проведение профилактических ветеринарно-санитарных мероприятий». В документе 


\section{Социально-экономический и әуманитарный журнал Красноярского ГАУ. 2019. № 4}

подчеркивалось, что указанные мероприятия должны были осуществляться под руководством главного ветеринарного врача города [14].

Было принято выделить необходимые помещения для организации ветеринарной лечебницы города [15].

Вместе с тем за неудовлетворительную организацию ветеринарной службы В.А. Олейникову был объявлен строгий выговор [16].

Несмотря на строгие требования местного органа власти, ни неотложные, ни срочные меры «к наведению должного порядка» ответственными лицами приняты так и не были.

Через два месяца на заседании исполкома повторно был рассмотрен вопрос о ветеринарном обслуживании скота и птицы, в том числе и в прикухонных хозяйствах УВСО.

В.А. Олейников доложил о том, что подготовка к зимнему содержанию скота в УВСО не ведется, кормо-кухня не работает, а ветеринарное обслуживание в прикухонных хозяйствах в/ч «поставлено слабо», так как не хватает ветеринарных врачей.

Председатель исполкома ЖГС Б.А. Гедройц высказал удивление «спокойным отношением» к сложившейся ситуации со стороны лиц, ответственных за ветеринарное обслуживание, которые по оценке Гедройца «к исполнению только приступили и не торопятся». Председатель исполкома ЖГС потребовал от СЭС немедленно запретить убой свиней в УВСО [17].

Осенью 1965 г. снова возникла угроза проникновения ящура в животноводческие хозяйства города. 19.11.1965 г. состоялось заседание исполкома, на котором был рассмотрен вопрос «О неотложных мерах по предупреждению заноса ящура на территорию города и поселков» [18].

На заседании было отмечено, что имеется серьезная угроза заноса ящура на территорию города. В целях предупреждения вспышки опасного заболевания территория города и близлежащих поселков, включая животноводческие хозяйства УВСО, была объявлена «угрожаемой по заносу ящура» [19].

При исполкоме ЖГС была создана чрезвычайная комиссия по борьбе с ящуром во главе с председателем исполкома Б.А. Гедройцем [20].

Планом мероприятий по профилактике ящура в городе и окружающих поселках предусматривалось проведение разъяснительной работы среди обслуживающего персонала подсобных хозяйств УВСО о важности проведения мероприятий по предотвращению заболевания ящуром [21].

Меры, принятые руководством города и ветеринарной службой, позволили не допустить повторения энзоотии при возникновении угрозы повторного заноса вируса ящура в 1965 г. [22].

Вышеизложенные факты свидетельствуют о том, что в организации ветеринарного надзора за свиноводческими хозяйствами войсковых частей Управления военно-строительных отрядов г. Железногорска (Красноярск-26) в первой половине 1960-х гг. можно выделить два этапа. 
На первом этапе в начале 1960-х гг. в свиноводческих хозяйствах УВСО, в силу недостаточного количества специалистов и отсутствия контроля со стороны главного ветеринарного врача города, надлежащий уход за животными не осуществлялся, вследствие этого имели место массовые заболевания и падеж свинопоголовья.

На втором этапе, к середине 1960-х гг., уровень санитарноветеринарного надзора за содержанием животных в прикухонных хозяйствах УВСО повысился и стал проводиться под контролем главного ветеринарного врача города.

В результате целенаправленной работы исполкома ЖГС, который при содействии ГК КПСС принимал практические меры к повышению роли главного ветеринарного врача города в организации ветеринарносанитарного надзора за совхозами УРСа, личным подсобным хозяйством, в том числе и за свиноводческими хозяйствами военностроительных частей, была проведена реорганизация ветеринарной службы.

Реорганизация общегородской ветеринарной службы и установление контроля за подсобными хозяйствами в/ч, а также вывод ряда свиноводческих хозяйств УВСО за пределы населенных пунктов, способствовали снижению уровня заболеваемости животных.

Принятые меры повысили санитарное благополучие территории города, а также прилегающих поселков, и позволили предотвратить повторный занос вируса ящура в животноводческие хозяйства в 1965 г.

\section{Литература}

1. Реут Г.А. Закрытые административно-территориальные образования Сибири: социализм за колючей проволокой: монография / Краснояр. гос. аграр. ун-т. - Красноярск, 2012. - 350 с.; Его же. Мобилизация трудовых ресурсов и организация жилищно-гражданского строительства в закрытых городах Сибири / Краснояр. гос. аграр. ун-т. - Красноярск, 2014. - 278 с.; Его же. Развитие совхоза УРСа в закрытом городе Сибири Железногорске в 1950- 1980-х гг. // Международный научно-исследовательский журнал. - 2014. - № 11-1 (30). - С. 101-102; Его же. Развитие совхоза в Зеленогорске в 1950-1980-х гг. // Современная наука: теоретический и практический взгляд: сб. ст. междунар. науч.-практ. конф. - Уфа, 2014. - С. 119-121; Его же. Организация свинооткорма в условиях закрытого города 1954-1965-е гг. // Социально-экономический и гуманитарный журнал Красноярского ГАУ. 2018. - № 1 (7). - С. 216- 223.

2. Павлюкевич P.B. Создание и развитие Красноярского совнархоза (1957- 1965 гг.) / Краснояр. гос. аграр. ун-т. - Красноярск, 2016. - 231 с.; Его же. Мясная промышленность Красноярского края в 19561965 гг. // Вестник Кемеровского государственного университета. 2019. - T. 2, № 21(78). - C. 342- 352. 


\section{Социально-экономический и әуманитарный журнал Красноярского ГАУ. 2019. № 4}

3. Реут Г.А. К вопросу использования труда военных строителей в ЗАТО Министерства Среднего Машиностроения (МСM) СССР // История образования и науки в Сибири: мат-лы всерос. науч. конф. с междунар. участием «История науки и образования» и «Значение исторического образования в развитии гражданского и патриотического сознания в современном российском обществе». Вып. 3 / отв. ред. В.И. Федорова; Краснояр. гос. пед. ун-т им. В.П. Астафьева. Красноярск, 2009. - С. 216.

4. Павлюкевич P.B. Создание и развитие Красноярского совнархоза (1957- 1965 гг.) / Краснояр. гос. аграр. ун-т. - Красноярск, 2016. C. 163.

5. ЖГА. Ф. Р-1. Оп. 1. Д. 274. Л. 6.

6. ЖГА. Ф. Р-1. Оп. 1. Д. 112. Л. 42.

7. ЖГА. Ф. Р-1. Оп. 1. Д. 125. Л. 7.

8. ЖГА. Ф. Р-1. Оп. 1. Д. 148. Л. 54.

9. ЖГА. Ф. Р-1. Оп. 1. Д. 167. Л. 19.

10. ЖГА. Ф. Р-1. Оп. 1. Д. 196. Л. 108.

11. ЖГА. Ф. Р-1. Оп. 1. Д. 239. Л. 42

12. ЖГА. Ф. Р-1. Оп. 1. Д. 283. Л. 35

13. ЖГА. Ф. Р-1. Оп. 1. Д. 274. Л. 6.

14. ЖГА. Ф. Р-1. Оп. 1. Д. 274. Л. 24.

15. ЖГА. Ф. Р-1. Оп. 1. Д. 274. Л. 25.

16. ЖГА. Ф. Р-1. Оп. 1. Д. 274. Л. 26.

17. ЖГА. Ф. Р-1. ОП. 1. Д. 278. Л. 4.

18. ЖГА. Ф. Р-1. Оп. 1. Д. 283. Л. 7.

19. ЖГА. Ф. Р-1. Оп. 1. Д. 283. Л. 36.

20.ЖГА. Ф. Р-1. Оп. 1. Д. 283. Л. 36.

21. ЖГА. Ф. Р-1. Оп. 1. Д. 283. Л. 38.

22.Pеут Г.А. Ликвидация вспышки ящура свиней в животноводческих хозяйствах Железногорска (Красноярска-26). 1965 гг. // Социальноэкономический и гуманитарный журнал Красноярского ГАУ. 2018. - № 3. - C. 216- 223.

\section{Literatura}

1. Reut G.A. Zakrytye administrativno-territorial'nye obrazova-nija Sibiri: socializm za koljuchej provolokoj: monografija / Krasnojar. gos. agrar. un-t. - Krasnojarsk, 2012. - 350 s.; Ego zhe. Mobilizacija trudovyh resursov i organizacija zhilishhno-grazhdanskogo stroitel'stva v zakrytyh gorodah Sibiri / Krasnojar. gos. agrar. un-t. - Krasnojarsk, 2014. - 278 s.; Ego zhe. Razvitie sovhoza URSa v zakrytom gorode Sibiri Zheleznogorske v 1950-1980-h gg. // Mezhdunarodnyj nauchno-issledovatel'skij zhurnal. - 2014. - № 11-1(30). - S. 101- 102; Ego zhe. Razvitie sovhoza v Zelenogorske v 1950-1980-h gg. // Sovremennaja nauka: teoreticheskij i prakticheskij vzgljad: sb. st. mezhdunar. nauch.-prakt. konf. - Ufa, 
2014. - S. 119-121; Ego zhe. Organizacija svinootkorma v uslovijah zakrytogo goroda 1954-1965-e gg. // Social'no-jekonomicheskij i gumanitarnyj zhurnal Krasnojarskogo GAU. - 2018. - № 1(7). - S. 216223.

2. Pavljukevich R.V. Sozdanie i razvitie Krasnojarskogo sovnarhoza (19571965 gg.) / Krasnojar. gos. agrar. un-t. - Krasnojarsk, 2016. - 231 s.; Ego zhe. Mjasnaja promyshlennost' Krasnojarskogo kraja v 1956- 1965 gg. // Vestnik Kemerovskogo gosudarstvennogo universiteta. - 2019. - T. 2, № 21(78). - S. 342- 352.

3. Reut G.A. K voprosu ispol'zovanija truda voennyh stroitelej v ZATO Ministerstva srednego mashinostroenija (MSM) SSSR // Istorija obrazovanija i nauki v Sibiri: mat-ly vseros. nauch. konf. s mezhdunar. uchastiem «Istorija nauki i obrazovanija» i «Znachenie istoricheskogo obrazovanija v razvitii grazhdanskogo i patriotiche-skogo soznanija v sovremennom rossijskom obshhestve». Vyp. 3 / otv. red. V.I. Fedorova; Krasnojar. gos. ped. un-t im. V.P. Astaf'eva. - Krasnojarsk, 2009. - C. 216.

4. Pavljukevich R.V. Sozdanie i razvitie Krasnojarskogo sovnarhoza (19571965 gg.) / Krasnojar. gos. agrar. un-t. - Krasnojarsk, 2016. - S. 163.

5. ZhGA. F. R-1. Op. 1. D. 274. L. 6.

6. ZhGA. F. R-1. Op. 1. D. 112. L. 42.

7. ZhGA. F. R-1. Op. 1. D. 125. L. 7.

8. ZhGA. F. R-1. Op. 1. D. 148. L. 54.

9. ZhGA. F. R-1. Op. 1. D. 167. L. 19.

10. ZhGA. F. R-1. Op. 1. D. 196. L. 108.

11. ZhGA. F. R-1. Op. 1. D. 239. L. 42.

12. ZhGA. F. R-1. Op. 1. D. 283. L. 35.

13. ZhGA. F. R-1. Op. 1. D. 274. L. 6.

14. ZhGA. F. R-1. Op. 1. D. 274. L. 24.

15. ZhGA. F. R-1. Op. 1. D. 274. L. 25.

16. ZhGA. F. R-1. Op. 1. D. 274. L. 26.

17. ZhGA. F. R-1. Op. 1. D. 278. L. 4.

18. ZhGA. F. R-1. Op. 1. D. 283. L. 7.

19. ZhGA. F. R-1. Op. 1. D. 283. L. 36.

20.ZhGA. F. R-1. Op. 1. D. 283. L. 36.

21. ZhGA. F. R-1. Op. 1. D. 283. L. 38.

22. Reut G.A. Likvidacija vspyshki jashhura svinej v zhivotnovodcheskih hozjajstvah Zheleznogorska (Krasnojarska-26). 1965 gg. // Social'nojekonomicheskij i gumanitarnyj zhurnal Krasnojarskogo GAU. - 2018. № 3. - S. 216- 223.

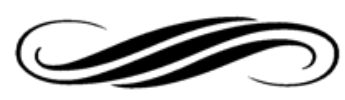

